University of Nebraska - Lincoln

DigitalCommons@University of Nebraska - Lincoln

$2-1-2003$

\title{
Estimating Soil Moisture Under Low Frequency Surface Irrigation Using Crop Water Stress Index
}

\author{
Paul D. Colaizzi \\ USDA-ARS, Paul.Colaizzi@ARS.USDA.GOV \\ Edward M. Barnes \\ USDA-ARS \\ Thomas R. Clarke \\ USDA-ARS \\ Christopher Y. Choi \\ University of Arizona \\ Peter M. Waller \\ University of Arizona
}

Follow this and additional works at: https://digitalcommons.unl.edu/usdaarsfacpub

Colaizzi, Paul D.; Barnes, Edward M.; Clarke, Thomas R.; Choi, Christopher Y.; and Waller, Peter M., "Estimating Soil Moisture Under Low Frequency Surface Irrigation Using Crop Water Stress Index" (2003). Publications from USDA-ARS / UNL Faculty. 1822.

https://digitalcommons.unl.edu/usdaarsfacpub/1822

This Article is brought to you for free and open access by the U.S. Department of Agriculture: Agricultural Research Service, Lincoln, Nebraska at DigitalCommons@University of Nebraska - Lincoln. It has been accepted for inclusion in Publications from USDA-ARS / UNL Faculty by an authorized administrator of DigitalCommons@University of Nebraska - Lincoln. 


\title{
Estimating Soil Moisture Under Low Frequency Surface Irrigation Using Crop Water Stress Index
}

\author{
Paul D. Colaizzi ${ }^{1}$; Edward M. Barnes ${ }^{2}$; Thomas R. Clarke ${ }^{3}$; Christopher Y. Choi ${ }^{4}$; and Peter M. Waller ${ }^{5}$
}

\begin{abstract}
The present study investigated the relationship between the crop water stress index (CWSI) and soil moisture for surface irrigated cotton (Gossypium hirsutum, Delta Pine 90b) at Maricopa, Arizona during the 1998 season. The CWSI was linked to soil moisture through the water stress coefficient $K_{s}$ that accounts for reduced crop evapotranspiration when there is a shortage of soil water. A stress recovery coefficient $K_{\text {rec }}$ was introduced to account for reduced crop evapotranspiration as the crop recovered from water stress after irrigation events. A soil water stress index (SWSI) was derived in terms of $K_{s}$ and $K_{\text {rec }}$. The SWSI compared reasonably well to the CWSI, but atmospheric stability correction for the CWSI did not improve comparisons. When the CWSI was substituted into the SWSI formulation, it gave good prediction of soil moisture depletion (fDEP; when to irrigate) and depth of root zone depletion $\left(D_{r}\right.$; how much to irrigate). Disagreement was greatest for fDEP $<0.6$ because cotton is less sensitive to water stress in this range.
\end{abstract}

DOI: $10.1061 /(A S C E) 0733-9437(2003) 129: 1(27)$

CE Database keywords: Soil moisture; Surface irrigation.

\section{Introduction}

The crop water stress index (CWSI) has been the subject of extensive research in the past 20 years to schedule irrigations using canopy temperature. By timing irrigations based on some threshold value, the CWSI can reduce water use without significant compromise to final yield (Wanjura et al. 1990; Shae et al. 1999). Furthermore, canopy temperature can be measured rapidly and non-invasively with portable infrared thermometers (IRTs), which are more reliable for detecting water stress than in situ soil moisture measurements (Jackson 1982). The CWSI and other canopy temperature-based indices, however, indicate when but not how much to irrigate. They are not uniquely correlated to the fraction of soil moisture depletion (fDEP), which is more practical and universally understood in timing and determining application depths (Martin et al. 1990) and for relating the effect of irrigation management strategies to yield (Hussman et al. 1998). Nonetheless, crop water use can be simulated because it is linked to mea-

\footnotetext{
${ }^{1}$ Agricultural Engineering, Conservation and Production Research Laboratory, U.S. Dept. of Agriculture/Agricultural Research Service, P.O. Drawer 10, Bushland, TX 79012.

${ }^{2}$ Agricultural Engineer, U.S., Water Conservation Lab., U.S. Dept. of Agriculture/Agricultural Research Service, 4331 East Broadway, Phoenix, AZ 85040.

${ }^{3}$ Physical Scientist, U.S. Water Conservation Lab., U.S. Dept. of Agriculture/Agricultural Research Service, 4331 East Broadway, Phoenix, AZ 85040.

${ }^{4}$ Associate Professor, Dept. of Agricultural and Biosystems Engineering, Univ. of Arizona, Tucson, AZ 85721.

${ }^{5}$ Associate Professor, Dept. of Agricultural and Biosystems Engineering, Univ. of Arizona, Tucson, AZ 85721.

Note. Discussion open until July 1, 2003. Separate discussions must be submitted for individual papers. To extend the closing date by one month, a written request must be filed with the ASCE Managing Editor. The manuscript for this paper was submitted for review and possible publication on April 12, 2001; approved on May 16, 2002. This paper is part of the Journal of Irrigation and Drainage Engineering, Vol. 129, No. 1, February 1, 2003. CASCE, ISSN 0733-9437/2003/1$27-35 / \$ 18.00$.
}

sured canopy temperature, allowing estimates of fDEP through a soil water balance (Hatfield et al. 1984; Kjelgaard et al. 1996; Barnes et al. 2000). Within-field variation in crop water use has been found to contribute to variation in crop yield, which is of interest in site-specific crop management (Sadler et al. 2000).

The present research investigates a more direct approach of relating fDEP to the CWSI. Jackson et al. (1981) related the CWSI to crop evapotranspiration $\left(\mathrm{ET}_{c}\right)$, where CWSI values greater than zero indicate reductions in $\mathrm{ET}_{c}$ below atmospheric demand (i.e., water stress). The Food and Agriculture Organization Paper No. 56 (FAO 56) (Allen et al. 1998) procedures compute $\mathrm{ET}_{c}$ as the product of reference evapotranspiration $\mathrm{ET}_{o}$ and a crop coefficient $K_{c}$. Reductions in $\mathrm{ET}_{c}$ below atmospheric demand are accounted for through a water stress coefficient $K_{s}$ that is included in the $K_{c}$ term. In FAO 56, the $K_{s}$ term for a given crop is a function of fDEP and atmospheric demand. Jensen et al. (1970) give another commonly used expression of $K_{s}$ as a function only of fDEP. By deriving a soil water stress index (SWSI) in terms of $K_{s}$, it is hypothesized that the CWSI can be related to fDEP through the $K_{s}$ term by assuming the SWSI and CWSI are equal. It is recognized, however, that the FAO 56 and Jensen formulations of the $K_{s}$ term do not account for a stress recovery period following irrigations. The CWSI does not always drop to zero immediately after an irrigation because the plant must regenerate itself after sufficient stress has occurred (Jackson et al. 1981; Jackson 1982). It is also possible that plant transpiration can be reduced by the lack of oxygen in the root zone for several days after a large volume of water is applied (Reicosky et al. 1985). Therefore, a stress recovery coefficient $K_{\text {rec }}$ is proposed to account for plant recovery.

The objectives of the present research are to investigate the relationship between the CWSI, $K_{s}$, and fDEP during a cotton season in Arizona, and to introduce the stress recovery coefficient $K_{\text {rec }}$. Additional objectives are to compare the CWSI using four calculation procedures (empirical CWSI and theoretical CWSI using three aerodynamic resistance models) and to evaluate two $K_{s}$ methods (FAO 56 and Jensen). The ultimate goal is to estimate fDEP by combining the CWSI with FAO 56 procedures using the 
best CWSI and $K_{s}$ calculation method. With fDEP known, the depth of root zone moisture depletion ( $D_{r}$, how much to irrigate) can be estimated.

\section{Calculation of Crop Water Stress Index}

The CWSI can be defined as

$$
\mathrm{CWSI}=\frac{\left(T_{c}-T_{a}\right)_{m}-\left(T_{c}-T_{a}\right)_{11}}{\left(T_{c}-T_{a}\right)_{\mathrm{ul}}-\left(T_{c}-T_{a}\right)_{11}}
$$

where $T_{c}=$ canopy temperature $\left({ }^{\circ} \mathrm{C}\right) ; T_{a}=$ air temperature $\left({ }^{\circ} \mathrm{C}\right) ; m$ indicates measured conditions, $11=$ lower limit (crop canopy transpiration not limited by available soil moisture); and ul=upper limit (nontranspiring crop). The empirical CWSI was computed according to Idso et al. (1981), where $\left(T_{c}-T_{a}\right)_{\mathrm{ll}}$ and $\left(T_{c}-T_{a}\right)_{\mathrm{ul}}$ were assumed functions of the atmospheric vapor pressure deficit using crop-specific, empirically determined coefficients. Empirical parameters for cotton were taken from the data presented by Idso (1982). The theoretical CWSI was computed according to Jackson et al. (1981), which uses surface energy balance relationships to define the lower and upper limits in Eq. (1). The lower and upper canopy resistance terms for cotton were assumed constant at 10 and $250 \mathrm{~s} \mathrm{~m}^{-1}$, respectively (Ehrler 1973; Keener and Gardner 1987).

The theoretical CWSI requires computation of the aerodynamic resistance $r_{a}$ term, which quantifies the resistance to energy transfer between the crop canopy and atmosphere. In general, resistance to energy transfer is enhanced or suppressed by forced and free convection, where the latter is usually expressed by atmospheric stability correction terms. The simplest $r_{a}$ models assume forced convention dominates and therefore neglect stability correction. This study compared three $r_{a}$ models, consisting of the Campbell model (with and without stability correction) and the Monteith model. Calculation procedures were nearly identical to those used by Kjelgaard et al. (1996). The Campbell model is given as (Campbell 1977)

$$
r_{a}=\frac{\left[\ln \left(\frac{z-d+z_{H}}{z_{H}}\right)+\psi_{H}\right]\left[\ln \left(\frac{z-d+z_{M}}{z_{M}}\right)+\psi_{M}\right]}{k^{2} u}
$$

where $z=$ anemometer height $(\mathrm{m}), d=$ zero plane displacement (m), $z_{H}$ and $z_{M}=$ roughness lengths for sensible heat and momentum $(\mathrm{m}), \psi_{H}$ and $\psi_{M}=$ stability correction factors for heat and momentum, respectively; $k=$ von Karman constant (0.41); and $u$ $=$ wind speed at height $z(2 \mathrm{~m})$. Both terms $d$ and $z_{M}$ can be estimated as functions of canopy height $h(1.2 \mathrm{~m}$ for cotton at full canopy), and $z_{H}$ as a function of $z_{M}$; i.e., $d=0.67 \mathrm{~h}, z_{M}$ $=0.13 \mathrm{~h}$, and $z_{H}=0.2 z_{M}$.

The stability correction factors $\psi_{H}$ and $\psi_{M}$ account for buoyancy effects on heat and momentum transfer that are suppressed or enhanced from the canopy-air temperature difference (e.g., Kustas et al. 1989). For stable conditions, the canopy temperature is less than the air temperature, and $\psi_{H}$ and $\psi_{M}$ are positive, increasing $r_{a}$ in Eq. (2). The opposite is the case for unstable (enhanced) conditions. The Campbell model without stability correction is simply $\psi_{H}=\psi_{M}=0$.

An expression for stable conditions is (Businger 1975)

$$
\psi_{H}=\psi_{M}=4.7 \zeta
$$

where $\zeta=$ atmospheric stability correction parameter, defined as

$$
\zeta=\frac{-k z g H}{\rho_{a} C_{p} T_{a} u^{* 3}}
$$

where $g=$ gravitational constant $\left(9.81 \mathrm{~m} \mathrm{~s}^{-2}\right) ; H=$ sensible heat $\left(\mathrm{W} \mathrm{m}^{-2}\right) ; \rho_{a}=$ density of dry air $\left(1.19 \mathrm{~kg} \mathrm{~m}^{-3}\right) ; C_{p}=$ specific heat of dry air $\left(1013 \mathrm{~J} \mathrm{~kg}^{-1}{ }^{\circ} \mathrm{C}^{-1}\right), T_{a}=$ air temperature $(\mathrm{K})$; and $u^{*}$ $=$ friction velocity $\left(\mathrm{m} \mathrm{s}^{-1}\right)$. Like $\psi_{H}$ and $\psi_{M}, \zeta>0$ for stable and $\zeta<0$ for unstable conditions. Sensible heat $H$ is

$$
H=\frac{\rho_{a} C_{p}\left(T_{c}-T_{a}\right)}{r_{a}}
$$

and $u^{*}$ is defined as (Campbell 1985)

$$
u^{*}=\frac{k u}{\ln \left[\frac{z-d+z_{M}}{z_{M}}\right]+\psi_{M}}
$$

Eq. (2) can be simplified by combining it with Eq. (6)

$$
r_{a}=\frac{\ln \left(\frac{z-d+z_{H}}{z_{H}}\right)+\psi_{H}}{k^{2} u^{*}}
$$

For unstable conditions, $\psi_{H}$ is given as (Kjelgaard et al. 1996)

$$
\psi_{H}=-2 \ln \left(\frac{1+\sqrt{1-16 \zeta}}{2}\right)
$$

and $\psi_{M}$ is given as (Campbell 1985)

$$
\psi_{M}=0.6 \psi_{H}
$$

The Monteith aerodynamic resistance model has a more empirical and computationally simpler approach for stability correction. It has the form (Monteith 1973)

$$
r_{a M}=\frac{\left[\ln \left(\frac{z-d}{z_{M}}\right)\right]^{2}}{k^{2} u}(1+n \mathrm{Ri})
$$

where $n=$ atmospheric condition number (assumed 5.2 and 4.5 for stable and unstable conditions, respectively); and $\mathrm{Ri}$ $=$ Richardson number, defined as

$$
\mathrm{Ri}=\frac{(z-d)\left(T_{a}-T_{c}\right)}{T u^{2}}
$$

where $T=$ average of the air and canopy temperature in Kelvin. For stable conditions, $\mathrm{Ri}$ is positive and results in an increase in $r_{a M}$ from Eq. (10). The opposite is the case for unstable conditions, where Ri becomes negative. From Eq. (11), the magnitude of $R$ indicates the relative roles of buoyancy (numerator) and forced convection (denominator).

Wind speeds below $2 \mathrm{~m} \mathrm{~s}^{-1}$ resulted in unrealistic values for $r_{a}$ in all three models. Therefore, $u=2 \mathrm{~m} \mathrm{~s}^{-1}$ was the minimum value used when observed wind speed was less.

\section{Crop Water Stress Index and Soil Moisture Relations}

The CWSI can be expressed in terms of latent heat flux (Jackson et al. 1981)

$$
\mathrm{CWSI}=1-\frac{\lambda \mathrm{ET}_{c}}{\lambda \mathrm{ET}_{p}}
$$

where $\lambda \mathrm{ET}_{c}$ and $\lambda \mathrm{ET}_{p}=$ instantaneous crop and potential crop evapotranspiration of a full canopy, respectively $\left(\mathrm{W} \mathrm{m}^{-2}\right)$. "Potential" refers to conditions where latent heat flux is limited only by atmospheric demands (e.g., soil moisture depletion is not lim- 
iting plant water uptake), so that as $\lambda \mathrm{ET}_{c} \rightarrow \lambda \mathrm{ET}_{p}, \mathrm{CWSI} \rightarrow 0$. Crop water stress is most detectable when atmospheric demand is at a diurnal maximum; therefore, IRT measurements are generally taken during afternoon hours (Jackson 1982). The ratio $\left(\lambda \mathrm{ET}_{c} / \lambda \mathrm{ET}_{p}\right)$ will therefore likely reach a daily minimum, particularly if a soil moisture deficit causes $\lambda \mathrm{ET}_{c}$ to fall below $\lambda \mathrm{ET}_{p}$. Assuming the instantaneous latent heat flux ratio during the maximum diurnal atmospheric demand is similar to the daily latent heat flux ratio (Jackson et al. 1983), and converting latent heat flux to depth, the ratio $\left(\mathrm{ET}_{c} / \mathrm{ET}_{p}\right)$ is substituted for $\left(\lambda \mathrm{ET}_{c} / \lambda \mathrm{ET}_{p}\right)$ in Eq. (12). The resulting expression is termed the soil water stress index because $\mathrm{ET}_{c}$ will be related to soil moisture:

$$
\mathrm{SWSI}=1-\frac{\mathrm{ET}_{c}}{\mathrm{ET}_{p}}
$$

The dual crop coefficient procedure of FAO 56 (Allen et al. 1998) gives $\mathrm{ET}_{c}$ as

$$
\mathrm{ET}_{c}=\mathrm{ET}_{o}\left(K_{\mathrm{cb}} K_{s}+K_{e}\right)
$$

where $\quad \mathrm{ET}_{o}=$ reference evapotranspiration $\left(\mathrm{mm} \mathrm{day}^{-1}\right) ; \quad K_{\mathrm{cb}}$ =basal crop coefficient; $K_{s}=$ water stress coefficient; and $K_{c}$ $=$ soil evaporation coefficient for sunlit bare soil. Since the CWSI is valid only for full canopy cover when soil background is absent (Jackson et al. 1981), evaporation from sunlit bare soil is negligible, and $K_{c}$ can be omitted from Eq. (14) (Allen et al. 1998).

A stress recovery coefficient $K_{\text {rec }}$ is proposed for this study to account for the time required for roots to regenerate and leaves to rehydrate following an irrigation, provided plants have become water stressed prior to the irrigation (Jackson et al. 1981; Jackson 1982). This is usually the case for low-frequency surface irrigation methods (i.e., 10-14 days) that prevail in Arizona; however, the $K_{\text {rec }}$ term may not be necessary for high frequency irrigation systems (e.g., sprinkler or microirrigation) where soil moisture is ideally maintained above water stress thresholds. Including $K_{\text {rec }}$ and omitting $K_{e}$ in Eq. (14) results in

$$
\mathrm{ET}_{c}=\mathrm{ET}_{o}\left(K_{\mathrm{cb}} K_{s} K_{\mathrm{rec}}\right) .
$$

Experimental data in the present study suggest that the recovery of $\mathrm{ET}_{c}$ is a logarithmic function of cumulative $\mathrm{ET}_{o}\left(\mathrm{CET}_{o}\right)$, but only up to some maximum cumulative $\mathrm{ET}_{o}$ when recovery is complete $\left(\mathrm{CET}_{o \text {-max }}\right)$. Therefore, the $K_{\text {rec }}$ term is defined as

$$
\begin{gathered}
K_{\mathrm{rec}}=1-\left(a \ln \left(\mathrm{CET}_{o}\right)+b\right) \quad \mathrm{CET}_{o} \leqslant \mathrm{CET}_{o-\max } \\
K_{\mathrm{rec}}=1 \quad \mathrm{CET}_{o}>\mathrm{CET}_{o-\max }
\end{gathered}
$$

where $a$ and $b=$ regression coefficients. The justification for Eq. (16) and regression procedures for $a$ and $b$ are presented later.

The $\mathrm{ET}_{p}$ term in Eq. (13) describes conditions where $\mathrm{ET}_{c}$ reaches a maximum possible value that is limited only by atmospheric demand [i.e., $K_{s}=K_{\text {rec }}=1$ in Eq. (15)], given by

$$
\mathrm{ET}_{p}=\mathrm{ET}_{o}\left(K_{\mathrm{cb}}\right)
$$

Substituting Eqs. (15) and (17) into Eq. (13) and simplifying, the SWSI is

$$
\mathrm{SWSI}=1-K_{s} K_{\mathrm{rec}} .
$$

Two methods of estimating $K_{s}$ were investigated. The FAO 56 procedure assumes $K_{s}$ is unity until the fDEP reaches a threshold $p$, then decreases linearly to zero when fDEP reaches 1.0

$$
\begin{gathered}
K_{s}=1 \quad \mathrm{fDEP} \leqslant p \\
K_{s}=\frac{1-\mathrm{fDEP}}{1-p} \quad \mathrm{fDEP}>p
\end{gathered}
$$

where $p=\mathrm{fDEP}$ threshold when the crop begins to experience water stress. If $\mathrm{ET}_{c}$ is different than $5 \mathrm{~mm}$ day $^{-1}, p$ can be adjusted as a function of $\mathrm{ET}_{c}$

$$
p=p_{\text {table } 22}+0.04\left(5-\mathrm{ET}_{c}\right)
$$

where $p_{\text {table } 22}=$ crop-specific value given in Table 22 of FAO 56, and $\mathrm{ET}_{c}$ units are $\left(\mathrm{mm} \mathrm{day}^{-1}\right)$. The $p_{\text {table } 22}$ values used in this study are 0.60 for initial and development stages (establishment to early boll formation) and 0.65 thereafter (Allen et al. 1998).

Jensen et al. (1970) give an expression for $K_{s}$ that is an asymptotic function of fDEP but independent of $\mathrm{ET}_{c}$

$$
K_{s}=\frac{\ln [(1-\mathrm{fDEP}) 100+1]}{\ln [101]}
$$

Eqs. (18) and (19) or (21) can be combined and solved for fDEP as a function of the SWSI. If the CWSI is substituted for the SWSI in the resulting expression, fDEP can be estimated using the CWSI. With fDEP known, the depth of root zone depletion $D_{r}$ is the product of fDEP and total available water (TAW) in the root zone, where $D_{r}$ is the basis of how much to irrigate. Total available water is (Allen et al. 1998)

$$
\mathrm{TAW}=1,000\left(\theta_{\mathrm{fc}}-\theta_{\mathrm{wp}}\right) Z_{r}
$$

where 1,000 converts TAW to $\mathrm{mm} ; \theta_{\mathrm{fc}}=$ soil moisture content $\left(\mathrm{m} \mathrm{m}^{-3}\right)$ at field capacity; $\theta_{\mathrm{wp}}=$ soil moisture content $\left(\mathrm{m} \mathrm{m}^{-3}\right)$ at wilting point; and $Z_{r}=$ effective rooting depth $(\mathrm{m})$. Fig. 1 is a flow chart of the procedures given to estimate fDEP and $D_{r}$ from the CWSI.

\section{Experimental Methods}

The experiment was conducted at the Univ. of Arizona, Maricopa Agricultural Center (latitude $33^{\circ} 04^{\prime} \mathrm{N}$, longitude $111^{\circ} 58^{\prime} \mathrm{W}, 361$ $\mathrm{m}$ mean sea level). Cotton (Gossypium hirsutum, cv. Delta Pine 90b, full season) was planted on 26 April 1998 [day of year (DOY) 116] on east-west raised beds spaced $1.0 \mathrm{~m}$ apart on a laser-leveled 1.3 ha field. The soil is classified as a Casa Grande series, with sandy loam or sandy clay loam textures (Post et al. 1988). The study was part of a larger remote sensing experiment consisting of two nitrogen levels in a random block design with 16 plots; however, measurements pertinent to this paper were made only in Plots 12 and 16 where nitrogen treatments were identical (140 $\mathrm{kg} \mathrm{ha}^{-1}$ was the seasonal total). The field was surface (gravity) irrigated by six alfalfa valves located along the West boundary of the field. Irrigations varied from 100 to $150 \mathrm{~mm}$ per application and were the same for both plots for each event; a total of nine surface irrigations occurred during the season. A linear move irrigation system with drop hoses was under construction concurrently during the experiment, but was not operational until September when irrigations were essentially complete. An additional three applications (5, 25, and $20 \mathrm{~mm}$ ) occurred during September using the linear system, but only the $5 \mathrm{~mm}$ application for Plot 12 occurred during the period considered in this paper.

A meteorological station was placed in Plot 12. Measurements consisted of incoming solar irradiance $R_{s}$, relative humidity, wind speed $u$, and air temperature $T_{a}$. Canopy temperature $T_{c}$ was measured using stationary IRTs placed in Plots 12 and 16. 


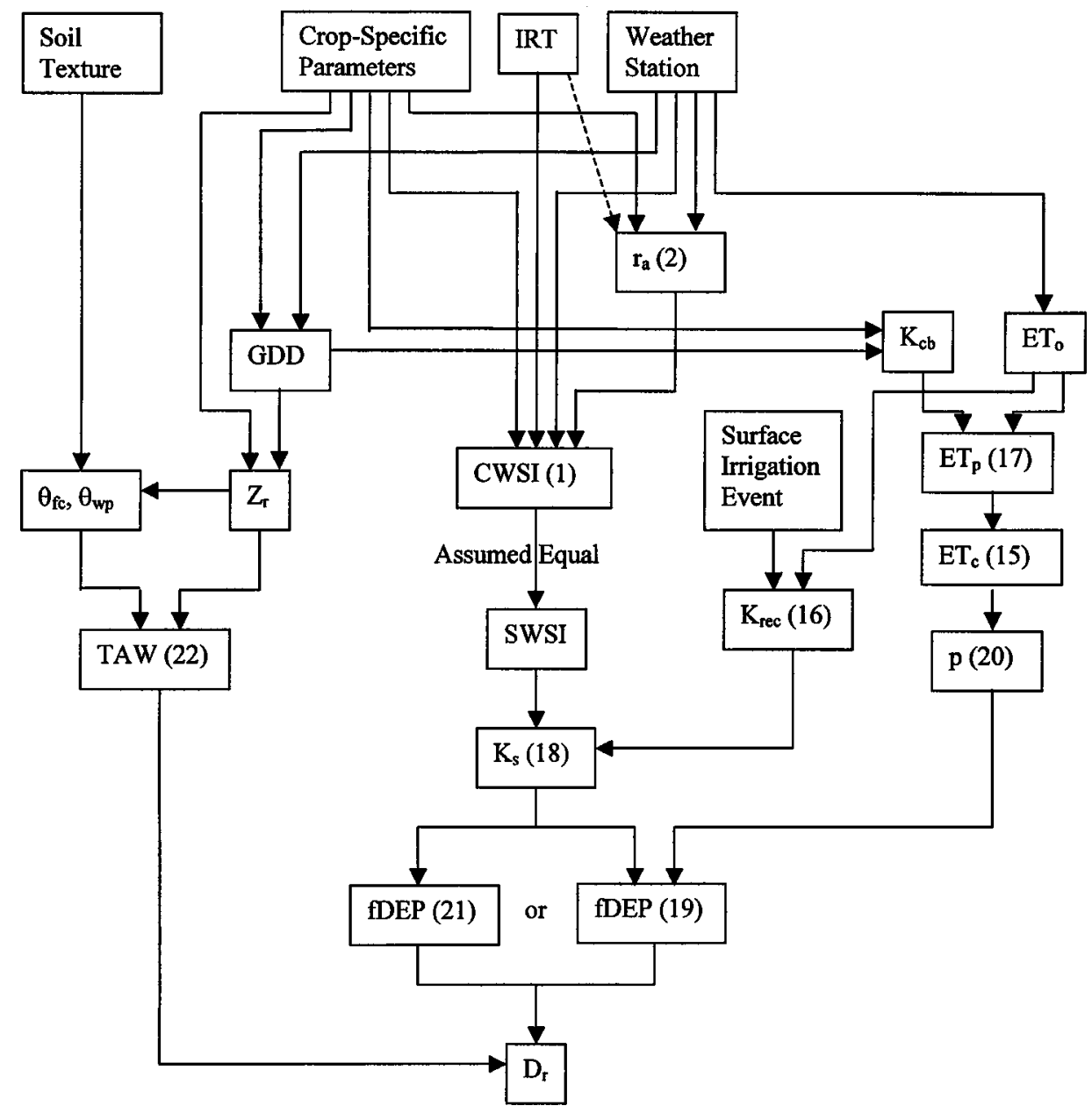

Fig. 1. Flow chart for estimating fraction of soil moisture depletion and $D_{r}$ from crop water stress index (parentheses refer to equations in text)

The IRTs (Model 3000.3 WLC, Everest, Tucson, Ariz.) were with custom $15^{\circ}$ field of view optics and viewed $50^{\circ}$ from nadir and $135^{\circ}$ azimuth, which was $45^{\circ}$ relative to the rows. This was to ensure that soil background would not influence $T_{c}$ measurements (Jackson et al. 1981). The IRTs were calibrated at the end of the season in a constant temperature room over a room temperature range of $5-45^{\circ} \mathrm{C}$ to an extended area blackbody (Model TEC-5-3, Advanced Kinetics, Huntington Beach, Calif.) where target temperatures were set from 0 to $70^{\circ} \mathrm{C}$ at $5^{\circ} \mathrm{C}$ intervals for each ambient temperature run. The calibration resulted in a polynomial for each IRT that determined the actual surface temperature as a function of the instrument body temperature and its reported apparent surface temperature. Meteorological and IRT measurements were recorded simultaneously every $15 \mathrm{~min}$ throughout the $24 \mathrm{~h}$ period during most of the season; IRT instrument height was $2.0 \mathrm{~m}$ from furrows. A daily CWSI value was obtained by averaging measurements between 1,400 and 1,600 h (Idso et al. 1982).

Volumetric soil moisture was measured using neutron scattering, a capacitance probe, and time domain reflectometry (TDR). Two neutron access tubes were placed in each plot; measurements were taken 2-3 times per week at depths $0.4-2.0 \mathrm{~m}$ from the surface in $0.2 \mathrm{~m}$ increments using a Campbell Pacific Nuclear (Martinez, Calif.) model 503 DR probe. A portable capacitance probe (Model ML1 - Theta Probe, Delta-T, Cambridge, U.K.) measured volumetric soil moisture in the top $0.05 \mathrm{~m}$ of the raised beds at five locations per plot two or three times per week. The TDR measurements consisted of four groups of probes perma- nently buried in each plot; each location had four probes at 0.05 , $0.10,0.15$, and $0.20 \mathrm{~m}$ depths. The TDR probes were multiplexed to a Tektronix (Beaverton, Ore.) model 1502C cable tester; volumetric soil moisture was retrieved every hour using the $T A C Q$ software program (Evett 1998). The upper and lower limits of volumetric soil moisture available to the crop (assumed field capacity $\theta_{\text {fc }}$ and wilting point $\theta_{\mathrm{wp}}$, respectively) were estimated at each location at $20 \mathrm{~cm}$ increments down to a $2 \mathrm{~m}$ depth by taking the maximum and minimum values observed during the season. For $\theta_{\mathrm{fc}}$, measurements were not considered until 3 days following a surface irrigation event to allow complete drainage by gravity throughout the root zone. For $\theta_{\mathrm{wp}}$, the cotton was severely stressed several times, especially on 24 August (DOY 236) when a broken pipe delayed irrigation. The estimated $\theta_{\mathrm{fc}}$ and $\theta_{\mathrm{wp}}$ ranged, respectively, from 0.08 to 0.13 and from 0.18 to 0.24 and were similar to those given by Post et al. (1988). The range in values was attributed to differences in both measured soil texture (sand contents ranged from 50 to $75 \%$ ) and in accounting for increases in rooting depths as the season progressed.

A soil water balance spreadsheet was used to estimate soil moisture between days of neutron measurements. Daily water use (i.e., crop evapotranspiration $\mathrm{ET}_{c}$ ) was estimated using Eq. (14). The $\mathrm{ET}_{o}$ term was calculated using the Penman-Monteith equation for a grass reference crop with daily time steps [Eq. (6) in FAO 56], and $K_{s}$ was calculated using Eqs. (19) or (21). Calculation of $K_{e}$ also followed FAO 56 procedures [Eqs. (71)-(75)]. This required knowing the fraction of vegetation cover $f_{c}$, which 
Table 1. Crop Development Stages and Basal Crop Coefficient $K_{\mathrm{cb}}$. Development Stage Nomenclature is Taken from Food and Agricultural Organization Paper 56 for Generic Crop, and Agronomic Stages for Cotton Are in Parentheses

\begin{tabular}{lccc}
\hline DOY & Date & Development stage & Cumulative GDD $\left({ }^{\circ} \mathrm{C}\right)$ \\
\hline 114 & 24 Apr & Plant & $K_{\mathrm{cb}}$ \\
$114-160$ & 24 Apr-9 Jun & Initial (establishment, early vegetative) & $0-440$ \\
$161-218$ & 10 Jun-6 Aug & Development (vegetative, flowering, early boll formation) & $440-1,320$ \\
$219-248$ & 7 Aug-5 Sep & Mid-Season (late flowering, mid-late boll formation) & $1,320-1,760$ \\
$249-284$ & 6 Sep-11 Oct & End (yield formation, ripening) & $1,760-2,200$ \\
310 & 6 Nov & Harvest & 1.15 \\
\hline
\end{tabular}

was estimated by weekly destructive plant sampling in three locations of each plot. The $K_{\mathrm{cb}}$ term is based on percentage of cumulative growing degree days (Slack et al. 1996) instead of percentage lengths of the growing season as specified in FAO 56. Values of $K_{\mathrm{cb}}$ vary linearly with cumulative growing degree days (GDDs) for the development (vegetative to early boll formation) and end (yield formation and ripening) stages; otherwise, $K_{\mathrm{cb}}$ is constant. Table 1 summarizes the crop development stage, cumulative GDDs, and basal crop coefficient $K_{\mathrm{cb}}$ values for the season. The mid-season $K_{\mathrm{cb}}$ value as given was corrected for local climatic conditions (Allen et al. 1998). Cumulative GDDs were calculated following the procedures of Snyder (1985), where the lower and upper threshold temperatures for cotton were 12.8 and $30.0^{\circ} \mathrm{C}$, respectively (Brown 1991). Effective rooting depths $Z_{r}$ were assumed to increase linearly from 0.15 to $1.4 \mathrm{~m}$ from planting up to the end of the mid-season development stage (Jensen et al. 1990). This assumption was supported by neutron scattering, in that soil moisture measurements remained fairly constant at depths beyond the assumed effective root zone.

The stress recovery coefficient $K_{\text {rec }}$ described in the previous section was used in calculating $\mathrm{ET}_{c}$ following the three irrigation events that occurred during the end of the development and midseason stages (late vegetative to late boll formation) when canopy cover was full $\left(f_{c} \approx 1\right)$. At this period in the season, evaporation from sunlit bare soil is negligible, resulting in $K_{e} \approx 0$ (Allen et al. 1998), and Eq. (14) becomes (15).

The CWSI was compared to the SWSI; comparisons are given in terms of slope, intercept, $r^{2}$, bias, and root mean squared error (RMSE). The CWSI was computed using four methods (empirical and theoretical using the three aerodynamic resistance models), and the SWSI was computed using two methods for $K_{s}$ [FAO 56 and Jensen models; i.e., Eqs. (19) and (21), respectively], making a total of eight comparisons. Using the most favorable comparison, the fDEP was estimated by substituting CWSI for SWSI in Eq. (18), combining with Eqs. (19) or (21), and solving for fDEP. The depth of root zone depletion $D_{r}$ was then computed as the product of fDEP and TAW in the root zone. The fDEP and $D_{r}$ estimated from the CWSI were then compared to those estimated from soil moisture measurements and the soil water balance. Measurements spanned from DOY 205 to 262 (late flowering to boll formation to early yield formation).

\section{Results and Discussion}

Table 2 summarizes the seasonal totals of irrigation, precipitation, actual, and potential evapotranspiration $\left(\mathrm{ET}_{c}\right.$ and $\left.\mathrm{ET}_{p}\right)$, and final lint yield for both plots. $\mathrm{ET}_{c}$ was computed from Eqs. (14) or (15), and $\mathrm{ET}_{p}$ is the upper limit of $\mathrm{ET}_{c}$ (i.e., $\left.K_{s}=K_{\text {rec }}=1\right)$. Irrigation totals for Plot 12 were $50 \mathrm{~mm}$ greater than Plot 16 because three irrigation events occurred in Plot 12 during September when testing the newly constructed linear move system. There was a 19 and $16 \%$ reduction in $\mathrm{ET}_{c}$ below $\mathrm{ET}_{p}$ in Plots 12 and 16, respectively, suggesting water availability was limited during the season, as $\mathrm{ET}_{c}$ more closely matched total irrigation depths. Final lint yield was about $15 \%$ greater in Plot 16 than Plot 12, not surprising since there were similar differences in $\mathrm{ET}_{c}$ (Doorenbos and Kassam 1979). The differences in $\mathrm{ET}_{c}$ may have been influenced by root development, which in turn may have been influenced by soil texture. Plot 12, for example, had more sand in the top $0.9 \mathrm{~m}$ of the soil profile than Plot 16. The differences in $\mathrm{ET}_{c}$ were established by the middle of the mid-season stage (boll formation), and they may have been even greater without the linear move irrigations in Plot 12.

Fig. 2 shows the time series of CWSI (no stability correction), SWSI (Jensen $K_{s}$ ), and irrigation and rainfall events from DOY 204 to DOY 264 for both plots without the stress recovery coefficient $K_{\text {rec }}$. During this period, there were four surface irrigation events; these occurred on DOY 204 (150 mm), DOY 216 (100 $\mathrm{mm})$, DOY $236(90 \mathrm{~mm})$, and DOY $247(130 \mathrm{~mm})$. There was also an irrigation on DOY $261(5 \mathrm{~mm})$ in Plot 12 using the linear move. Measurable rain occurred on DOY 229 (3 mm), DOY 240 (3 $\mathrm{mm})$, and DOY $250(5 \mathrm{~mm})$. The 3 days when rain occurred were eliminated from the analysis because clouds and the corresponding cooling effect on canopy temperatures prevented the detection of water stress. DOY 245 was also eliminated because of drizzle and overcast skies, although total rain was too small to be measurable. Four other days (DOY 204, 224, 263, and 264) were eliminated because of instrument malfunctions. A total of 53 days were considered for this study. Immediately after the irrigations on DOY 204, 216, and 236, the SWSI dropped below 0.05; however, the CWSI remained above SWSI for about 5 days. This was not observed immediately after the irrigation on DOY 247, which was at the end of the mid-season stage (late boll formation). The level of stress reached on DOY 247 was somewhat less than on DOY 216 and 236 (possibly because of overcast skies on DOY 245 and intermittent clouds on DOY 246-247), and the root volume was probably more developed. Both factors may have influenced the much quicker recovery time. However, CWSI on DOY 247 was similar to that observed on DOY 216 for Plot 16, when a recovery time was noticeable.

Table 2. Total Water Application, Potential Crop Water Use $\left(\mathrm{ET}_{p}\right)$, actual Crop Water Use $\left(\mathrm{ET}_{c}\right)$, and Lint Final Yield

\begin{tabular}{lcc}
\hline & Plot 12 & Plot 16 \\
\hline Irrigation (mm) & 1,120 & 1,070 \\
Rain (mm) & 25 & 25 \\
$\operatorname{ET}_{p}(\mathrm{~mm})$ & 1,220 & 1,220 \\
$\operatorname{ET}_{c}(\mathrm{~mm})$ & 990 & 1,020 \\
$\operatorname{Lint}(\mathrm{kg} / \mathrm{ha})$ & 1,150 & 1,360 \\
\hline
\end{tabular}



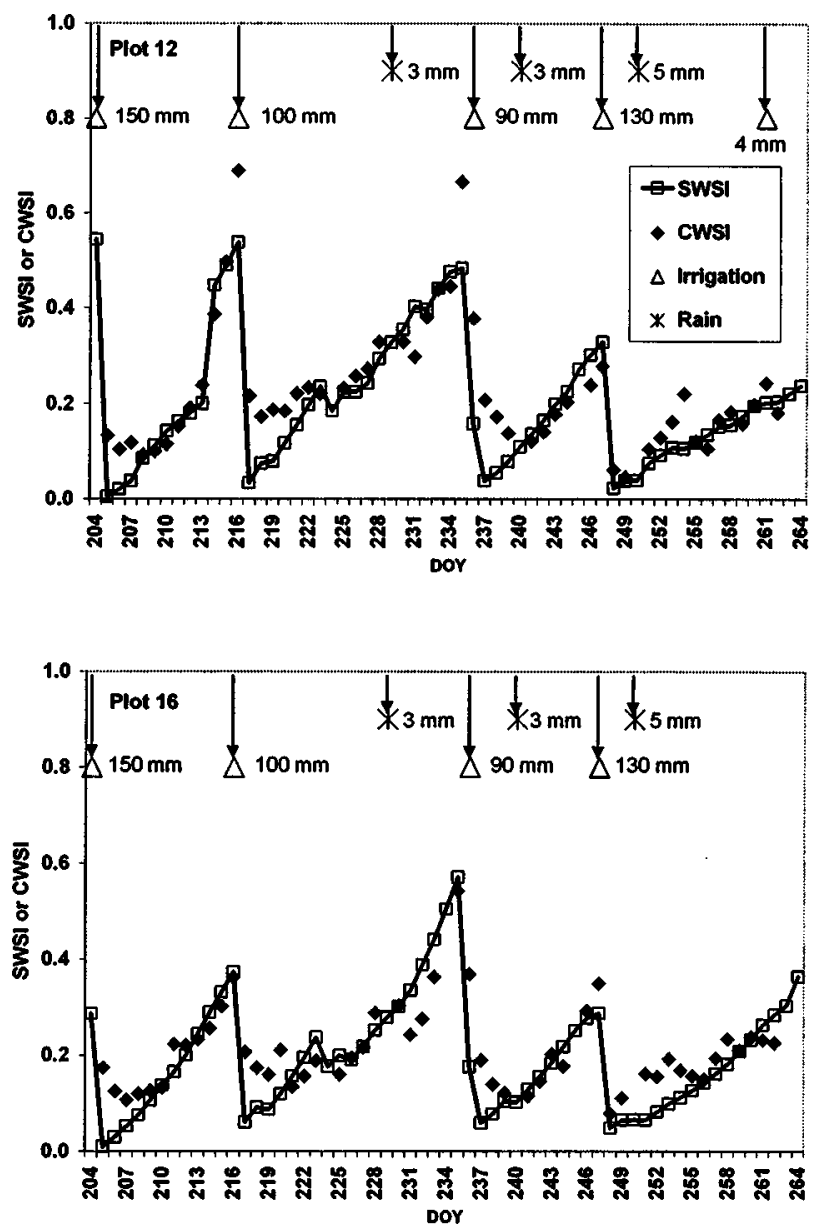

Fig. 2. Time series of soil water stress index (Jensen $K_{s}$ ), crop water stress index (no stability correction), irrigation applications, and rainfall events for 1998 season without recovery coefficient $\left(K_{\text {rec }}\right)$.

Fig. 3 shows (CWSI-SWSI) from Fig. 2 versus cumulative $\mathrm{ET}_{o}$ after the three irrigations on DOY 205, 216, and 236 for both plots. The difference appears to decrease logarithmically until the cumulative $\mathrm{ET}_{o}$ reaches about $55 \mathrm{~mm}$, then levels off. Regressions of CWSI-SWSI were performed for cumulative $\mathrm{ET}_{o}$ from 40 to $120 \mathrm{~mm}$ in $5 \mathrm{~mm}$ increments, and the highest $r^{2}(0.80)$

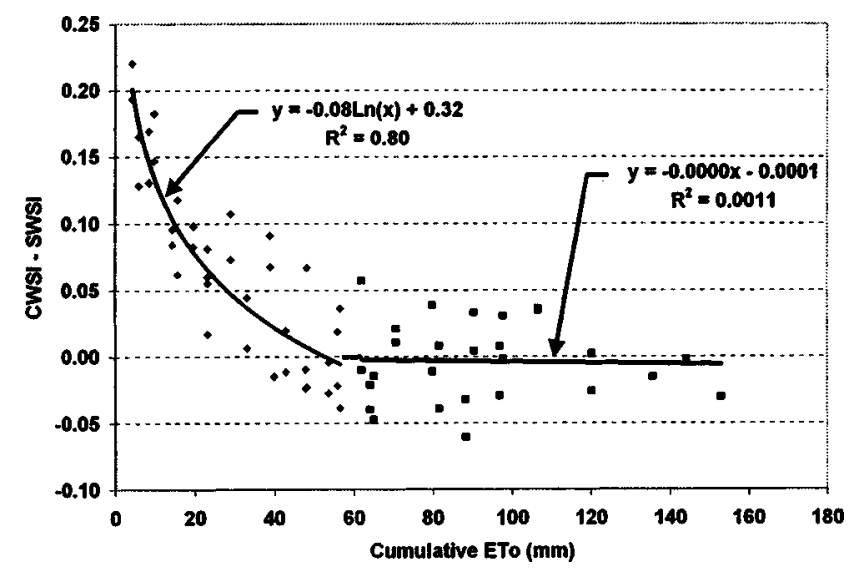

Fig. 3. Plot of (crop water stress index-soil water stress index) versus cumulative reference evapotranspiration $\mathrm{ET}_{o}$ after irrigations, with regression coefficients used for the recovery coefficient $K_{\text {rec }}$.
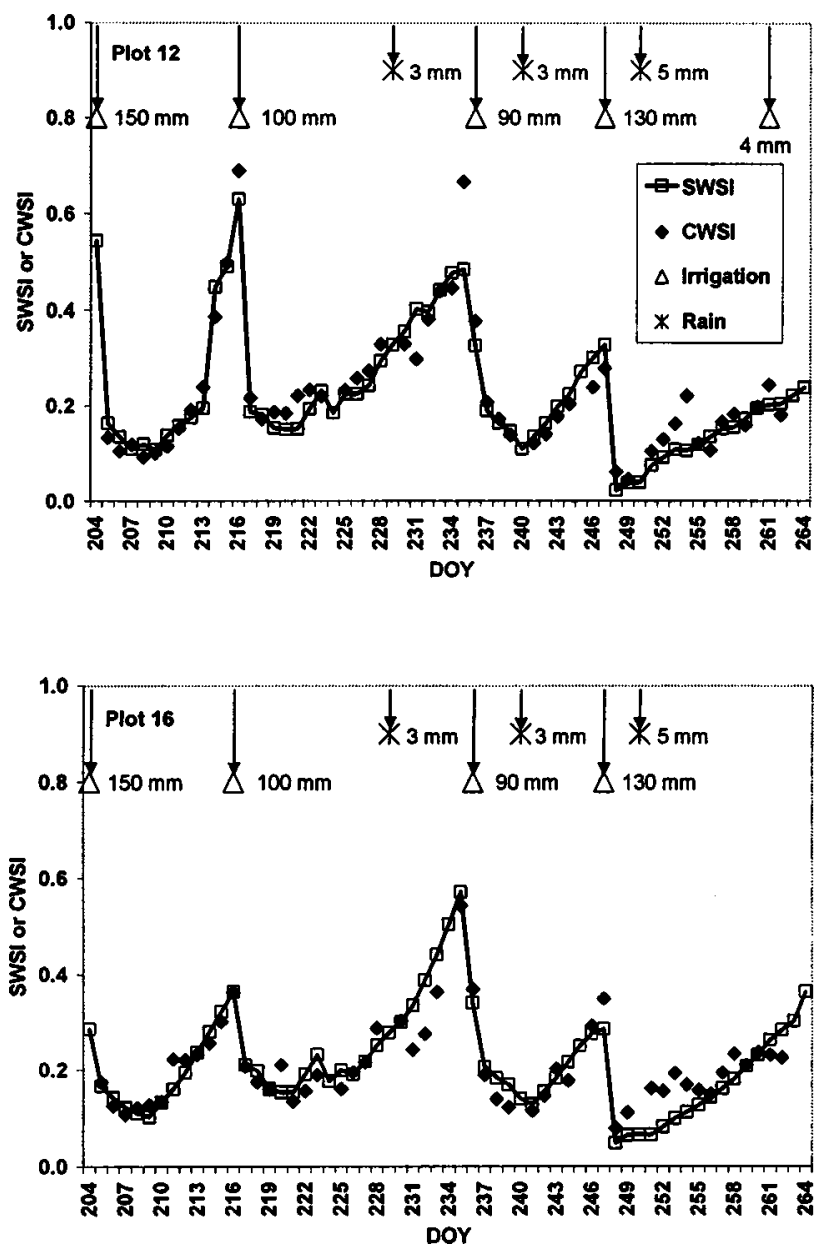

Fig. 4. Time series of soil water stress index (Jensen $K_{s}$ ), crop water stress index (no stability correction), irrigation applications, and rainfall events for 1998 season with recovery coefficient $K_{\text {rec }}$

occurred when cumulative $\mathrm{ET}_{o}$ was $55 \mathrm{~mm}$. The resulting empirical constants $a$ and $b$ were -0.08 and 0.32 , respectively. Another regression was performed for CWSI-SWSI when cumulative $\mathrm{ET}_{o}$ was equal to or greater than $55 \mathrm{~mm}$, and no relationship between CWSI-SWSI and cumulative $\mathrm{ET}_{o}$ was observed. The $a$ and $b$ values obtained from regression were used in Eq. (15), and the SWSI was recomputed using Eq. (17). Fig. 4 is identical to Fig. 2, except the SWSI now reflects the computations using $K_{\text {rec }}$. Comparing Figs. 2 and 4 during the 5 days after the irrigations on DOY 204, 216, and 236 shows closer agreement between SWSI and CWSI, and suggests the importance of accounting for stress recovery. The present study, however, is merely an initial attempt, and future efforts should focus on more rigorous development of the $K_{\text {rec }}$ term under a variety of irrigation management schemes.

In Fig. 4, the CWSI was greater than the SWSI several times despite the inclusion of $K_{\text {rec }}$. One instance occurred in Plot 12 just before the irrigation on DOY 236, but not in Plot 16. It was noted in Table 2 that total $\mathrm{ET}_{c}$ for the season was less for Plot 12, possibly the result of different root volumes and soil textures, which may explain this difference. Differences also occurred on DOY 211 (Plot 16), DOY 219-222 (DOY 220 only for Plot 16), DOY 249 (Plot 16), and DOY 251-254. High winds may have broken the stems of outer leaves, which could increase plant stress. The average daily wind run was $48.5 \mathrm{~km} \mathrm{day}^{-1}$ from DOY 204 to 264. Wind runs recorded on DOY 211, 219, 246, 252, and 
Table 3. Linear Regression Analysis Between Soil Water Stress Index and Crop Water Stress Index

\begin{tabular}{lcccrrrr}
\hline CWSI method & $r_{\mathrm{a}}$ method & $K_{\mathrm{s}}$ method & Slope & Intercept & $r^{2}$ & Bias & RMSE \\
\hline Empirical & N/A & FAO 56 & 0.41 & -0.04 & 0.50 & -0.193 \\
Theoretical & No Stabil. Corr. & FAO 56 & 0.39 & 0.12 & 0.70 & -0.044 \\
Theoretical & Campbell & FAO 56 & 0.42 & 0.06 & 0.65 & -0.094 \\
Theoretical & Monteith & FAO 56 & 0.41 & 0.14 & 0.62 & -0.013 & 0.166 \\
Empirical & N/A & Jensen & 0.94 & -0.13 & 0.59 & -0.144 \\
Theoretical & No Stabil. Corr. & Jensen & 0.91 & 0.02 & 0.86 & 0.163 \\
Theoretical & Campbell & Jensen & $1.00^{\mathrm{a}}$ & -0.04 & 0.82 & -0.045 \\
Theoretical & Monteith & Jensen & $0.96^{\mathrm{a}}$ & 0.04 & 0.77 & 0.049 \\
\hline
\end{tabular}

${ }^{\text {a }}$ Slopes were not significantly different than $1.0(\alpha=0.05)$.

254 were all greater than $80 \mathrm{~km} \mathrm{day}^{-1}$. The CWSI was less than the SWSI on DOY 231-233 (following rain on DOY 229), and on DOY 246-247 for Plot 12 (following drizzle on DOY 245). These underestimates may have been caused by intermittent clouds during the time of measurement. Cloud passages reduced $R_{S}$ by $50 \%$ or more, and several minutes may be required for the canopy temperature to reach equilibrium following a change in $R_{s}$ (Pennington and Heatherly 1989).

Table 3 gives regression statistics between CWSI and SWSI. The CWSI without stability correction compared most favorably to the SWSI using the Jensen $K_{s}$ model, having an intercept closest to zero, the best correlation, the least bias, and least RMSE. Fig. 5 shows the $x y$ scatter. The Campbell stability correction method, however, resulted in a slope closest to one. Only the Campbell and Monteith stability correction methods using the Jensen $K_{s}$ model had slopes that were not significantly different from one; intercepts for all methods were significantly different from zero $(\alpha=0.05)$. Stability correction did not improve CWSI comparisons. Kjelgaard et al. (1996) reached a similar conclusion after comparing the canopy temperature energy balance to the Bowen ratio energy balance.

Eqs. (18) and (21) (Jensen $K_{s}$ model) were combined and solved for fDEP, where the CWSI without stability correction was substituted for SWSI in Eq. (18). The resulting fDEP was com-

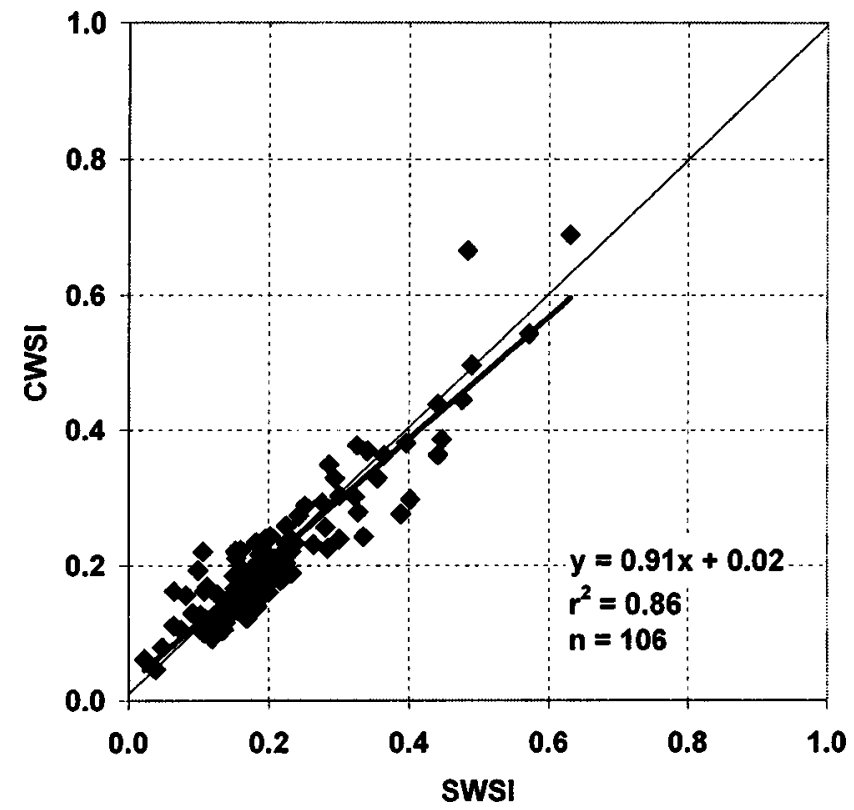

Fig. 5. Scattergram of crop water stress index (no stability correction) versus soil water stress index $\left(\right.$ Jensen $\left.K_{s}\right)$ pared to that estimated from in situ soil moisture measurements and the soil water balance. Fig. 6 shows the $x y$ scatter. With TAW known from Eq. (22), $D_{r}$ was estimated as the product of TAW and fDEP, and a similar comparison can be made (Fig. 7). Statistical results of these comparisons are summarized in Table 4. Correlation $\left(r^{2}\right)$ was similar to the comparisons between CWSI and SWSI; however, for fDEP the intercept, bias, and RMSE were about two times greater. The slope and intercept values for the fDEP and $D_{r}$ comparisons were both significantly different from one and zero, respectively $(\alpha=0.05)$.

In Fig. 6, greater error is observed for in situ fDEP below 0.6. A similar trend is observed in Fig. 7 for $D_{r}$ less than about 80 $\mathrm{mm}$. This can be explained by Fig. 8, where $K_{s}$ is plotted as a function of fDEP. The FAO 56 and Jensen models are shown along with $K_{s}$ points estimated from the CWSI by substituting CWSI for SWSI in Eq. (18) and solving for $K_{s}$. When fDEP is less than about $0.6, K_{s}$ is relatively insensitive; however, $K_{s}$ falls off rapidly as fDEP increases over 0.6. This results in a similar relationship between the CWSI and fDEP, in that small errors of CWSI will lead to larger errors in fDEP when soil moisture in the root zone is relatively plentiful. In a cotton cultivar study, Lacape et al. (1998) also observed that the CWSI did not change appreciably until fDEP reached $0.5-0.6$. Finally, Fig. 8 shows that $K_{s}$ points estimated from the CWSI agree more closely with the

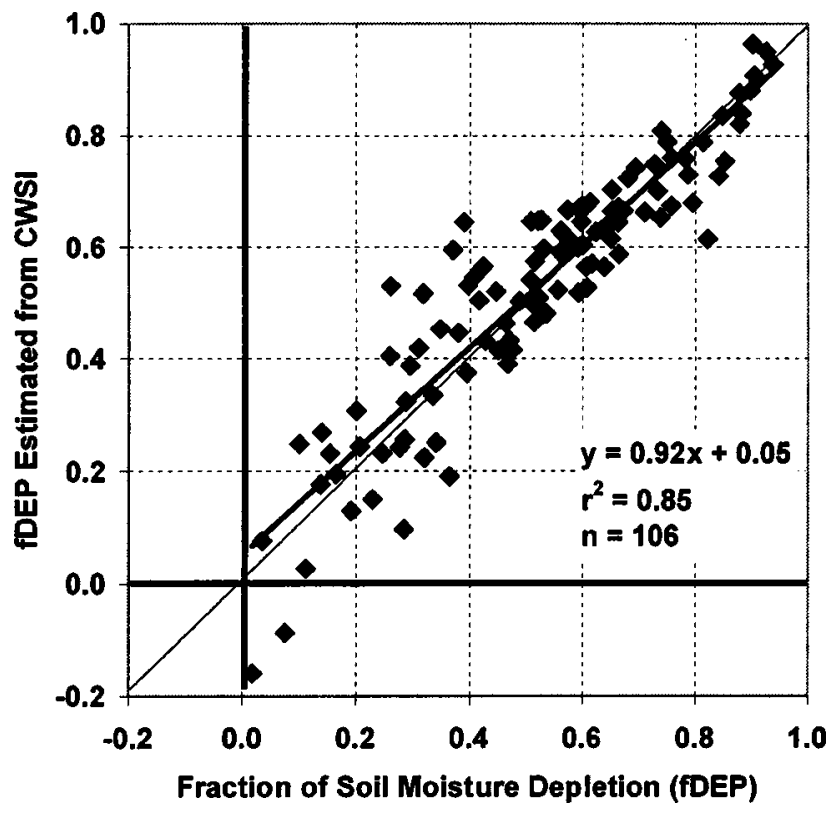

Fig. 6. Scattergram of fraction of soil moisture depletion (estimated from crop water stress index versus in situ measurements) 


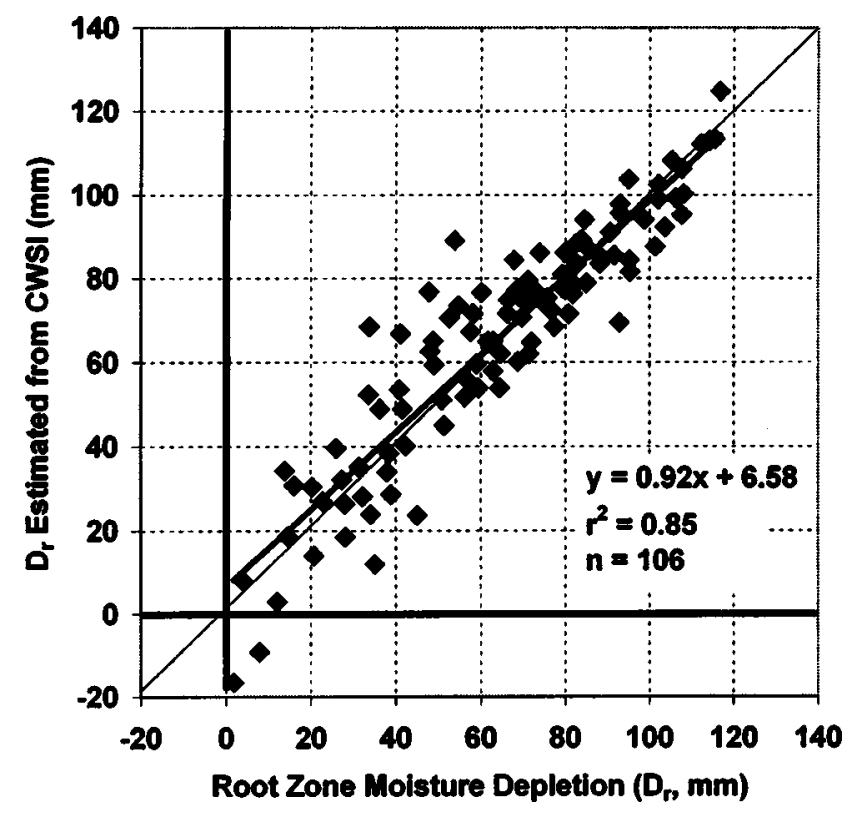

Fig. 7. Scattergram of fraction of root zone depletion $\left(D_{r}\right)$ (estimated from crop water stress index versus in situ measurements)

Jensen than the FAO $56 K_{s}$ model, which explains the better comparisons between the CWSI and the SWSI using the Jensen $K_{s}$ model.

\section{Conclusions}

A procedure to estimate soil moisture depletion (fDEP, when to irrigate) and the fraction of root zone depletion $\left(D_{r}\right.$, how much to irrigate) using the remotely sensed CWSI was demonstrated. The procedure was tested for low frequency surface irrigated cotton in Maricopa, Ariz., and performed reasonably well. Stability correction in calculating aerodynamic resistance $r_{a}$ did not improve estimates. The CWSI was linked to in situ measurements of soil moisture through the water stress coefficient $K_{s}$. The Jensen $K_{s}$ model resulted in much better correlation between the CWSI and soil moisture than the FAO $56 K_{s}$ model.

A water stress recovery coefficient $K_{\text {rec }}$ was introduced and accounted for about $20 \%$ reduction in actual to potential evapotranspiration immediately after irrigations as observed through the remotely sensed CWSI. The $K_{\text {rec }}$ term should undergo more rigorous development; however, it may not be necessary under high frequency irrigation, such as sprinkler or drip, where fDEP is maintained at levels above water stress thresholds.

Disagreement was greater for fDEP ranges below about 0.6 because $K_{s}$ is less sensitive to changes in fDEP in this range. Consequently, this procedure may not perform well for high frequency irrigation because soil moisture is usually maintained at higher levels. Other possible sources of error included intermit-

Table 4. Regression Statistics for Estimating Fraction of Soil Moisture Depletion and Root Zone Depletion $D_{r}$ Using Theoretical Crop Water Stress Index (No Stability Correction, Jensen $K_{s}$ Method)

\begin{tabular}{lccccr}
\hline & Slope & Intercept & $r^{2}$ & Bias & RMSE \\
\hline fDEP & 0.92 & 0.05 & 0.85 & 0.01 & 0.08 \\
$D_{r}(\mathrm{~mm})$ & 0.92 & 6.58 & 0.85 & 1.51 & 10.52 \\
\hline
\end{tabular}

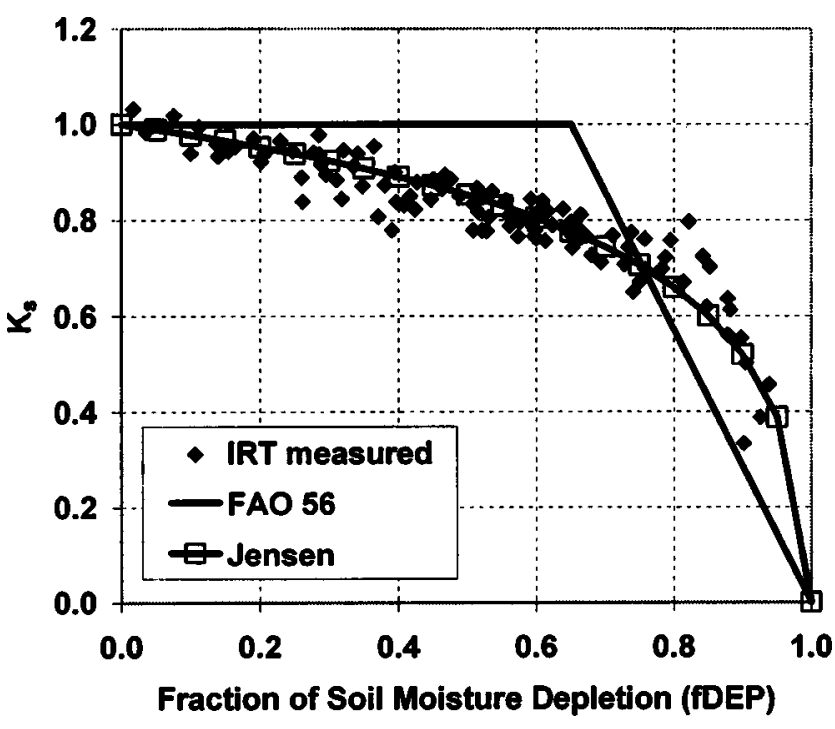

Fig. 8. Water stress coefficient $K_{s}$ versus measured fraction of soil moisture depletion in root zone.

tent clouds, broken leaf stems following high winds, low atmospheric demand following rain, and estimates of effective root depths used in the soil water balance.

The use of the CWSI, which is a remote sensing technique, to estimate fDEP and $D_{r}$ could greatly improve irrigation management and lead to greater water use efficiency. This is an important goal for irrigated agriculture as competition for water resources, land, and pressure to lessen environmental impacts are expected to increase in the coming decades. The next step is to test this procedure in real-time irrigation management for different crops, locations, climates, and irrigation practices.

\section{Acknowledgments}

The writers gratefully acknowledge the Idaho National Engineering and Enviromental Laboratory for their support of this research. Mention of a trade name, proprietary product, or specific equipment does not constitute a guarantee or warranty by the writers or their affiliations and does not imply approval of a product to the exclusion of others that may be suitable.

\section{References}

Allen, R. G., Pereira, L. S., Raes, D., and Smith, M. (1998). "Crop evapotranspiration." Irrigation and Drainage Paper No. 56, Food and Agriculture Organization of the United Nations, Rome.

Barnes, E. M., Pinter, Jr., P. J., Kimball, B. A., Hunsaker, D. J., Wall, G. W., and LaMorte, R. L. (2000). "Precision irrigation management using modeling and remote sensing approaches." Proc., 4th National Irrigation Symp., Phoenix, ASAE, St. Joseph, Mich., 332-337.

Brown, P. W. (1991). "Normal values of heat unit accumulation for Southern Arizona." Arizona Cooperative Extension, Rep. No. 190041, Univ. of Arizona, Tucson, Ariz.

Businger, J. A. (1975). "Aerodynamics of vegetated surfaces." Heat and mass transfer in the biosphere, Part 1, Transfer processes in the plant environment, D. A. de Vries and N. H. Afgan, eds., Halstead, New York, 139-165.

Campbell, G. S. (1977). An introduction to environmental biophysics, Springer, New York. 
Campbell, G. S. (1985). Soil physics with BASIC: Transport models for soil-plant systems, Elsevier, New York.

Doorenbos, J., and Kassam, A. H. (1979). "Yield response to water." Irrigation and Drainage Paper No. 33, Food and Agricultural Organization of the United Nations, Rome.

Ehrler, W. (1973). "Cotton leaf temperatures as related to soil water depletion and meteorological factors." Agron. J., 65, 404-409.

Evett, S. R. (1998). "The TACQ computer program for automatic measurement of water content and bulk electrical conductivity using time domain reflectometry." ASAE Paper No. 983182, St. Joseph, Mich.

Hatfield, J. L., Reginato, R. J., and Idso, S. B. (1984). "Evaluation of canopy temperature: Evapotranspiration models over various crops." Agric. Forest Meteorol., 32, 41-53.

Hussman, S., Johnson, K., Wegener, R., and Metzler, F. (1998). "Upland cotton lint yield response to several soil moisture depletion levels." Cotton: A College of Agriculture Rep., Publ. AZ1006, College of Agriculture, Univ. of Arizona, Tucson, Ariz.

Idso, S. B. (1982). "Non-water stressed baselines: A key to measuring and interpreting plant water stress." Agric. Meterol., 27, 59-70.

Idso, S. B., Jackson, R. D., Pinter, Jr., P. J., Reginato, R. J., and Hatfield, J. L. (1981). "Normalizing the stress-degree parameter for environmental variability." Agric. Meterol., 24, 45-55.

Idso, S. B., Reginato, R. J., and Farah, S. M. (1982). "Soil- and atmosphere-induced plant water stress in cotton as inferred from foliage temperatures." Water Resour. Res., 18, 1143-1148.

Jackson, R. D. (1982). "Canopy temperature and crop water stress.” Advances in irrigation, D. Hillel, ed., Vol. 1, Academic, New York, 4385.

Jackson, R. D., Hatfield, J. L., Reginato, R. J., Idso, S. B., and Pinter, Jr., P. J. (1983). "Estimation of daily evapotranspiration from one timeof-day measurements." Agric. Water Manage., 7, 351-362.

Jackson, R. D., Idso, S. B., Reginato, R. J., and Pinter, Jr., P. J. (1981). "Canopy temperatures as a crop water stress indicator." Water Resour. Res., 17, 1133-1138.

Jensen, M. E., Burman, R. D., and Allen, R. G. (1990). "Evapotranspiration and irrigation water requirements." ASCE Manuals and Rep. on Engineering Practice No. 70, ASCE, New York.

Jensen, M. E., Robb, D. C. N., and Franzoy, C. E. (1970). "Scheduling irrigations using climate-crop-soil data." J. Irrig. Drain. Eng., 96(1), $25-38$.

Keener, M. E., and Gardner, B. (1987). "CWSI and stomatal resistance of cotton and soybeans." Proc., Irrigation and Drainage Division, Portland, Ore., ASCE, New York, 560-567.
Kjelgaard, J. F., Stockle, C. O., and Evans, R. G. (1996). "Accuracy of canopy temperature energy balance for determining daily evapotranspiration." Irrig. Sci., 16, 149-157.

Kustas, W. P., Choudhury, B. J., Moran, M. S., Reginato, R. J., Jackson, R. D., Gay, L. W., and Weaver, H. L. (1989). "Determination of sensible heat flux over sparse canopy using thermal infrared data." Agric. Forest Meteorol., 44, 197-216.

Lacape, M. J., Wery, J., and Annerose, D. J. M. (1998). "Relationship between plant and soil water status in five field-grown cotton (Gossypium hirsutum L.) cultivars." Field Crops Res., 57(1), 29-43.

Martin, D. L., Stegman, E. C., and Fereres, E. (1990). "Irrigation scheduling principles." Management of farm irrigation systems, G. J. Hoffman, T. A. Howell, and K. H. Solomon, eds., ASAE, St. Joseph, Mich., 155-203.

Monteith, J. L. (1973). Principles of environmental physics, Edward Arnold, London.

Pennington, D. A., and Heatherly, L. (1989). "Effects of changing solar radiation on canopy-air temperatures of cotton and soybeans." Agric. Forest Meteorol., 46, 1-14.

Post, D. F., Mack, C., Camp, P. D., and Suliman, A. S. (1988). "Mapping and characterization of the soils on the University of Arizona Maricopa Agricultural Center." Proc., Hydrology and Water Resources in Arizona and the Southwest, Arizona-Nevada Academy of Science, Tucson, Ariz., 49-60.

Reicosky, D. E., Smith, R. C. G., and Meyer, W. S. (1985). "Foliage temperature as a means of detecting stress of cotton subjected to a short-term water-table gradient." Agric. Forest Meteorol., 35, $193-$ 203.

Sadler, E. J., Bauer, P. J., Busscher, W. J., and Millen, J. A. (2000). "Site-specific analysis of a droughted corn crop: II. Water use and stress." Agron. J., 92(3), 403-410.

Shae, J. B., Steele, D. D., and Gregor, B. L. (1999). "Irrigation scheduling methods for potatoes in the Northern Great Plains." Trans. ASAE, 42(2), 351-360.

Slack, D. C., Martin, E. C., Sheta, A. E. A., Fox, Jr., F. A., Clark, L. J., and Ashley, R. O. (1996). "Crop coefficients normalized for climatic variability with growing-degree-days." Proc., Int. Conf. on Evapotranspiration and Irrigation Scheduling, San Antonio, Tex., ASAE, St. Joseph, Mich., 892-898.

Snyder, R. L. (1985). "Hand calculating degree days." Agric. Forest Meteorol., 35, 353-358.

Wanjura, D. F., Hatfield, J. L., and Upchurch, D. R. (1990). "Crop water stress index relationships with crop productivity." Irrig. Sci., 11, $93-$ 99. 